\title{
Pneumomediastinum and subcutaneous emphysema after unilateral salpingo-oophorectomy: A case report
}

\author{
Gülhan Kurtoğlu Çelik*, Tolga Öz, Güllü Ercan Haydar, Havva Şahin Kavaklı, Ferhat İçme, Uğur Özkula \\ ${ }^{a}$ Department of Emergency Medicine, Atatürk Training and Research Hospital, Ankara, Turkey
}

\begin{tabular}{lll}
\hline ARTICLE INFO & ABSTRACT \\
\hline $\begin{array}{l}\text { Article History } \\
\text { Received }\end{array} 19 / 07 / 2013$ & $\begin{array}{l}\text { Pneumomediastinum is characterized by localized air in mediastinum after perforation of } \\
\text { organs of respiratory system or digestive system and it is associated with many disease such } \\
\text { as blunt trauma, barotrauma, retropharyngeal abscess, acute asthma attack, Boerhaave } \\
\text { Accepted }\end{array} \quad 08 / 10 / 2013$ & $\begin{array}{l}\text { syndrome. We present a 48 year old female patient who had pneumomediastinum } \\
\text { after left salphingo-oophorectomy and we wanted to increase awareness of emergency } \\
\text { physicians about diagnosis and treatment of postoperative pneumomediastinum. }\end{array}$ \\
\hline * Correspondence to: &
\end{tabular}

\section{Gülhan Kurtoğlu Çelik}

Department of Emergency Medicine,

Atatürk Training and Research Hospital,

Ankara, Turkey

e-mail: kurtoglugulhan@yahoo.com

\section{Keywords:}

Abdominal pain

Emergency medicine

Pneumomediastinum

Postoperative period

\section{Introduction}

Pneumomediastinum characterized by localized air in mediastinum after perforation of organs of respiratory system or digestive system is described from Hamman in 1939 (Demirel et al., 2008). Pneumomediastinum is associated with many precipitating factors, such as smoking, exposure to anesthetic agent and many disease such as blunt trauma, barotrauma, retropharyngeal abscess, acute asthma attack, Boerhaave syndrome (Ramia et al., 1999). Pneumomediastinum is also a rare complication of diverticulitis, toxic megacolon, bowel perforation can be occured after surgery, and colonoscopy (Yaşar et al., 2011). In addition, pneumomediastinum emerging after colonic perforation is seemed very rare. Also, peritoneal irritation symptoms can be a sign of intraperitoneal free perforation, signs of irritations can remains hidden in retroperitoneal perforations according to the localization of perforation. Abscess and colonic gas can be in various localizations according to their anatomic placement, and may present with atypical clinical symptoms. When approaching to diagnosis, this atypical symptoms can lead to difficulties. Undiagnosed and untreated patients are associated with high morbidity and mortality (Choi, 2011).

In this article, while reporting a patient determined pneumomediastinum after left salphingo-oophorectomy, we wanted to increase awareness of emergency physicians about diagnosis and treatment of postoperative pneumomediastinum.

\section{Case}

Our case was a 48 years old female patient who admitted to the emergency department with complaints of abdominal pain lasting for 10 days. We learned that she had undergone salpingo-oophorectomy surgery due to ovarian cyst, 14 days ago and she was discharged without any complication on postoperative $4^{\text {th }}$ day. She was nulliparous, in postmenopausal period, and had salphingo-oophorectomy and total hysterectomy in medical history. On general evaluation the symptoms of abdominal pain were at the forefront, therefore 


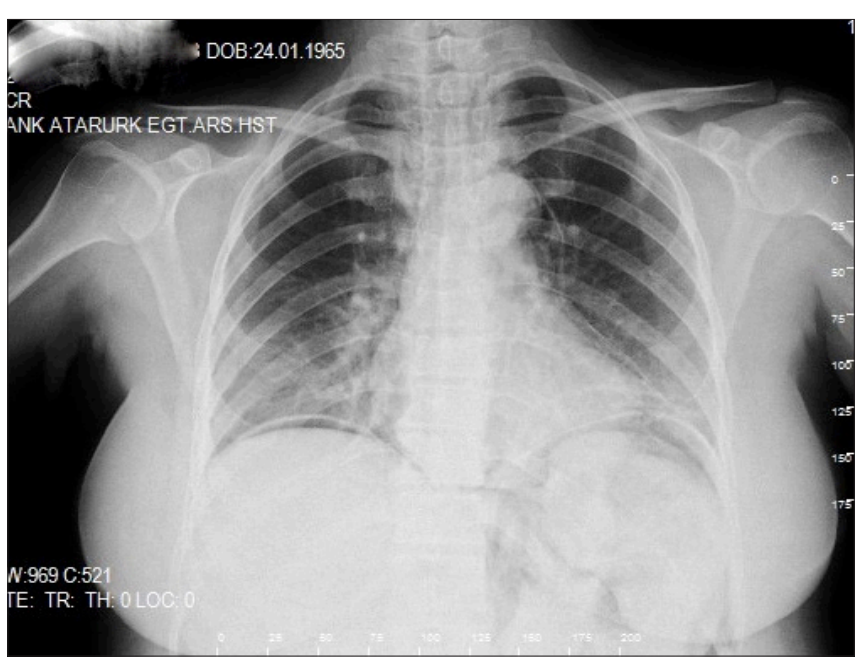

Fig. 1. Image of subcutaneous emphysema and free air belonging to the chest X-ray of patient

respiratory symptoms remained in the shade. On physical examination, the only symptom associated with the respiratory system was crepitus in the left lateral area. The other findings included abdominal tenderness, significant defense in lower left quadrant, and decreased bowel sounds and incision scars of previous operations were present. In complete blood count, hemoglobin level was $9.6 \mathrm{gr} / \mathrm{dL}$, white blood cell count was $19.4810^{3} / \mu \mathrm{L}$ and neutrophil dominated. Biochemical test results were, alanine aminotransferase (ALT): $30 \mathrm{U} / \mathrm{L}$, aspartate aminotransferase (AST): $38 \mathrm{U} / \mathrm{L}$, gamma-glutamyl transferase (GGT): $64 \mathrm{U} / \mathrm{L}$, total bilirubin: $0.50 \mathrm{mg} / \mathrm{dL}$, direct bilirubin: $0.37 \mathrm{mg} / \mathrm{dL}$, sodium: $135 \mathrm{mmol} / \mathrm{L}$, potassium: 3.2 $\mathrm{mmol} / \mathrm{L}$, calcium $7.4 \mathrm{mg} / \mathrm{dL}$. The patient's ECG and arterial blood gas $(\mathrm{ABG})$ values were normal. Image of subcutaneous emphysema and free air belonging to the chest X-ray of patient shown in (Fig. 1). On direct abdominal graphy, free air under the diaphragm in the right and non leveling diffuse gas in the left colonic segments were observed. On computed tomography (CT), secretory densities extending to pelvis on the left middle and distal levels in a $25 \mathrm{~cm}$ segment, retroperitoneal abscess collections and values of air compatible with colon perforation, values of air in the left lateral abdominal wall and in the rectus muscle (Fig. 2) and diffuse values of air in mediastinum including the sections and paracardiac fatty tissue plans were visible (Fig. 3). The

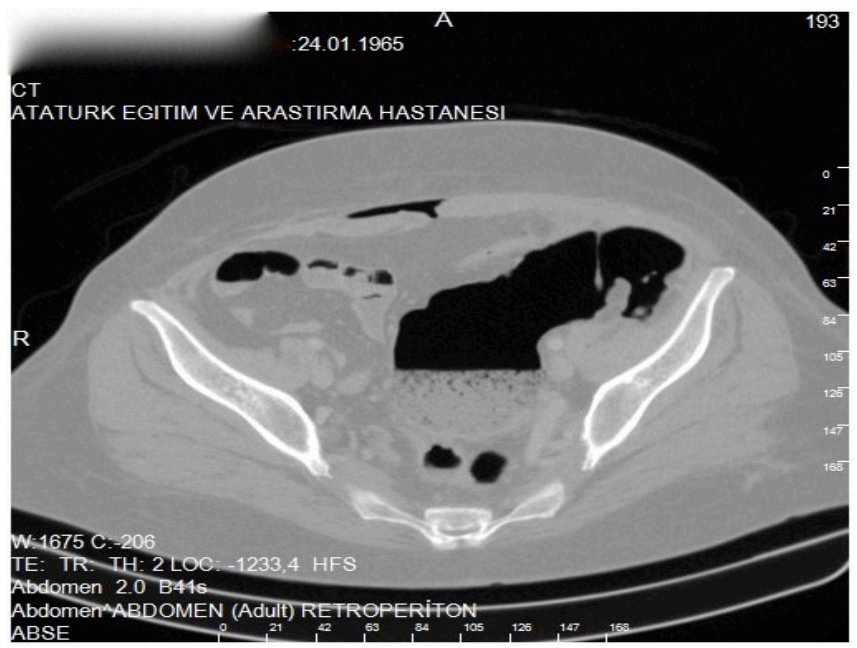

Fig. 2. Retroperitoneal abscess collections and values of air compatible with colon perforation patient was hospitalized in the department of Obstetrics and Gynecology on these findings, and intra-abdominal abscess was detected by laparotomy. Pretracheal fasciotomy intended for subcutaneous emphysema was performed by the thoracic surgery. Cefazolin sodium, piperacillin sodium and tazobactam were administered parenterally to the patient. Regression in pneumomediastinum was observed on control CT scans taken after two days. There was no complication in postoperative follow-up of the patient.

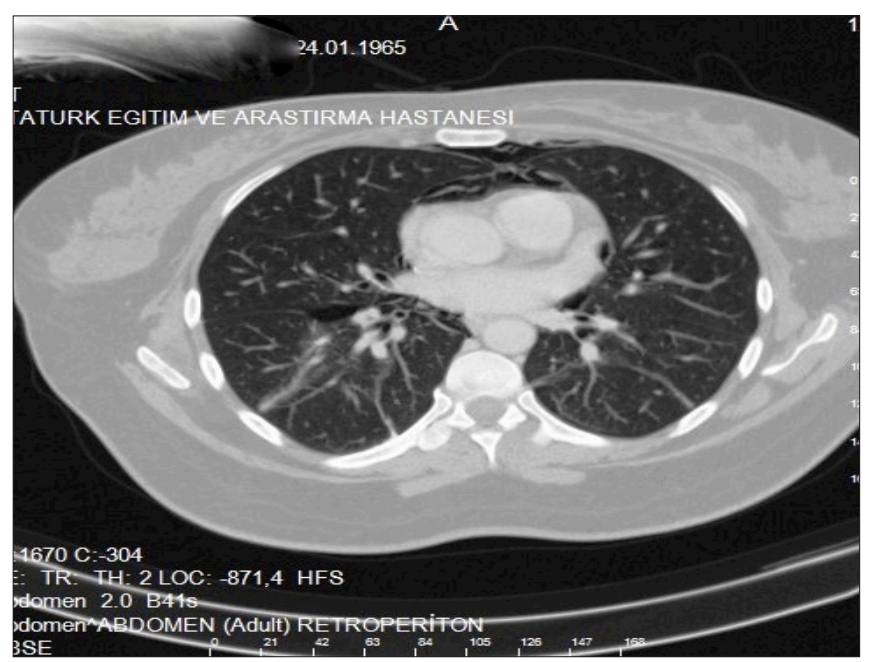

Fig. 3. Diffuse values of air in mediastinum including the sections and paracardiac fatty tissue plans were visible.

\section{Discussion and conclusion}

Pneumomediastinum secondary to an intra-abdominal operation is a rare postoperative complication and it is relatively uncommon in the literature (Hu et al., 2013).

Pneumomediastinum is often caused by alveolar rupture causing a seperation through bronchoalveolar case and filling of air into the mediastinum. Air can pass through the abdomen or thorax in many ways, retroperitoneal air can be seemed whether direct perforation of colon or dissection of intramural colonic air (pneumatosis coli) through the retroperitoneum and advancing into retroperitoneum through mesentery proper. After entering the retroperitoneum, air can move into mediastinum along the fascial plans. By way of rupture of mediastinal pleura, air depletion through the pleural cavity can cause pneumothorax (Marwan et al., 2007).

Mediastinum is involved in various anatomical structures including submandibular region, retropharyngeal area, and vascular bed in the neck. It is also linked to retroperitoneal region through peri-aortic and peri-esophageal areas. The tissue structure beginning from the mediastinum, extends through sterno-costal area of the diaphragm and to the pelvis through side walls of the abdomen. Although mediastinum is only a limited region in the rib cage, as defined above, it is involved with a very wide area (Zylak et al., 2000). For this reason, free air in the mediastinum in patients with pneumomediastinum may spread through all of these interrelated areas.

The most common causes of pneumomediastinum include thoracic trauma, emesis, and foreign body aspiration. Pneumomediastinum may occur due to diverticulitis (Soliani et al., 2002; Besic et al., 2004), ulcerative colitis, toxic megacolon (Mogan et al., 1980), colonoscopy (Goerg and Düber, 1996), endoscopic polypectomi (Ho et al., 1996) and 
more rarely spontaneously (Pretre and Rohner, 1992). It is also reported that prisoners were tearing oral mucosa and causing subcutaneous emphysema and pneumomediastinum by Valsalva maneuver, in order to be hospitalized and escape from the negative conditions of prisons (Meron and Kurkciyan, 2002).

Complications seen after salpingo-oophorectomy include bleeding, infection, abscess formation, urether and bowel injury and intraperitoneal adhesions. Pneumomediastinum presented in our case is a rarely encountered complication. In this patient, the diagnosis of pneumomediastinum due to colonic perforation and intra-abdominal abscess after salpingo-oophorectomy suggests that physicians should be careful in terms of pneumomediastinum in the differential diagnosis in this group of patients.

In pneumomediastinum there may be no symptoms as well as mild to moderate symptoms, such as chest pain, changes in voice, cough and stridor. Subcutaneous emphysema in the neck or crackling sound of the heart during systole (Hamman's sign) suggest the presence of pneumomediastinum. (Wintermark and Schnyder, 2001; Brunett et al., 2010). Pneumomediastinum should be considered in the differential diagnosis of chest pain in healthy adolescents and young adults. Chest radiography and CT are sufficient for diagnosis. In our case, chest radiography and computed tomography were taken due to clinical findings of subcutaneous emphysema. As a result of whole clinical signs, history and radiological findings, diagnosis of pneumomediastinum has been clarified.

After the surgical interventions were performed by related departments, the treatment of Pneumomediastinum is administered in accordance with the conservative approach described in the literature including monitoring of vital signs, oxygen supplementation, bed rest and supportive treatment (Park et al., 2013). In addition appropriate antibiotics therapy also provided against fatal complications, such as septicemia, mediastinitis.

As a result, patients admitted to the emergency department with abdominal pain with a history of recent abdominal surgery should be examined comprehensively and detailed investigations should be made taking into account the anatomical neighborhoods. Emergency medical doctors should be well-informed about the diagnosis and treatment of pneumomediastinum, especially in patients with postoperative complaints.

\section{REFERENCES}

Besic, N., Zgajnar, J., Kocijancic I., 2004. Pneumomediastinum, pneumopericardium, and pneumoperitoneum caused by peridiverticulitis of the colon. report of a case. Dis Colon Rectum. 47, 766-768.

Brunett, P.H., Yarris, L.M., Cevik, A.A., 2011. Pulmonary trauma. In Tintinalli’s Emergency Medicine: A Comprehensive Study Guide, Vol. 258, J.E., Kelen G.D.,Stapczynski J.S, eds. Mc Graw-Hill, New York, pp. 1744-1758.

Choi, P. W., 2011. Pneumomediastinum caused by colonic diverticulitis perforation. J. Korean Surg. Soc. 80, 17-20.

Demirel, A., Aynacı, E., Özgül, M.A., Özgül, G., Uysal, M.A., 2008. Primary spontaneous pneumomediastinum. Solunum. 10, 71-73.

Goerg, K.J., Düber C., 1996. Retroperitoneal, mediastinal and subcutaneous emphysema with pneumothorax after colonoscopy. Dtsch. Med. Wochenschr. 121, 693-693.

Ho, H.C., Burchell, S., Morris, P., Yu, M., 1996. Colon perforation, bilateral pneumothoraces, pneumopericardium, pneumomediastinum, and subcutaneous emphysema complicating endoscopic polypectomy: Anatomic and management considerations. Am. Surg. 62, 770-774.

Hu, M., Green, R., Gungor, A., 2013. Pneumomediastinum and subcutaneous empysema from bronchial foreign body aspiration. Am. J. Otolaryngol.Head and Neck Medicine and Surgery. 34, 85-88.

Marwan, K., Farmer, K.C., Varley, C., Chapple, K.S., 2007. Pneumothorax, pneumomediastinum, pneumoperitoneum, pneumoretroperitoneum and subcutaneous emphysema following diagnostic colonoscopy. Ann. R. Coll Surg. Engl. 89, 20-21.

Meron, G., Kurkciyan, K.T.I., 2002 Self-induced subcutaneous emphysema and pneumomediastinum. Chest. $122,386$.

Mogan, G.R., Sachar, D.B., Bauer, J., Salky, B., Janowitz, H.D., 1980. Toxic megacolon in ulcerative colitis complicated by pneumomediastinum: Report of two cases. Gastroenterology. 79, 559-562.

Park, J.M., Park, Y.C., Lee, J.N., Bae, J.S., 2013. Pneumomediatinum after functional endoscopic sinüs surgery-A case report. Korean J. Anesthesiol. 64, 367-372.

Prêtre, R., Rohner, A., 1992. Pneumomediastinum and subcutaneous cervical emphysema as signs of rectosigmoid perforation. Gastroenterol. Clin. Biol. 16, 460-462.

Ramia, J.M., Pardo, R., Cubo, T., Padilla, D., Hernandez-Calvo, J., 1999. Pneumomediastinum as a complication of extraperitoneal laparoscopic inguinal hernia repair. JSLS. 3, 233-234.

Soliani, G., Dominici, M., Bergossi, L., Basaglia, E., Pauli, S., Carcoforo, P., 2002. Acute colon diverticulitis in multiple myeloma patient: An unusual presentation of a colonic perforation. Case report. Ann. Ital. Chir. 73, 643-646.

Wintermark, M., Schnyder, P., 2001. The Macklin effect: A frequent etiology for pneumomediastinum in severe blunt chest trauma. Chest. 120, 543.

Yaşar, N.F., Kebapçı, M., İhtiyar, E., 2011. Pneumomediastinum and subcutaneous emphysema caused by sigmoid diverticulum perforation secondary to blunt abdominal trauma: Report of a case. Ulus Travma Acil Cerrahi Derg. 17, 93-95.

Zylak, C.M., Standen, J.R., Barnes, G.R., Zylak, C.J., 2000. Pneumo- mediastinum revisited. Radiographics. 20, $1043-1057$. 